\section{Molecular rearrangements}

Isotopes in Organic Chemistry. Volume 1: Isotopes in Molecular Rearrangements. Edited by E. Buncel and C. C. Lee. Pp.xvi+301. (Elsevier Scientific: Amsterdam, Oxford and New York, 1975.) Dfl.100; $\$ 41.75$.

LABELLING experiments have often been crucial to the development and understanding of modern organic chemistry and few will question after reading this book that many mechanistic studies would be considerably harder, if not impossible, without the availability of isotopic techniques. Nonetheless, good texts and reviews of this field have been thin on the ground; this series, of which the pre- sent volume is the first, should fill an important gap in the chemical literature.

Both carbonium ion (26 pages) and carbanion (105 pages) rearrangements are given another airing by N. C. Deno and D. H. Hunter, respectively, and pericyclic reactions (33 pages) are reviewed by W. R. Dolbier: J. S. Swenton's contribution concerns photochemically initiated rearrangements (51 pages) and $J$. L. Holmes deals with rearrangements occuring alongside mass spectral fragmentations (73 pages). As one might expect from these particular authors, of whom all have made significant contributions to their specialised topics, their articles are well-written from an authoritative standpoint, and all seem to cover the literature up to 1973. Generally, the authors have written a fairly descriptive text of the kind usually appreciated by organic chemists and have attempted (with varying success) to relate the isotopic results to other mechanistic criteria. The editors have avoided the obvious pitfall of allowing repititious theoretical introductions to each chapter, so the amount of worthwhile information in high.

This book (and probably the series, too) is written for the specialist with a deep interest in organic mechanistic studies. Elsevier might seriously have considered making each chapter available separately, particularly as the contents of the present volume span such a wide range of interests. Nonetheless, I strongly recommend the text as a valuable addition to any chemical library.
B. C. Challis

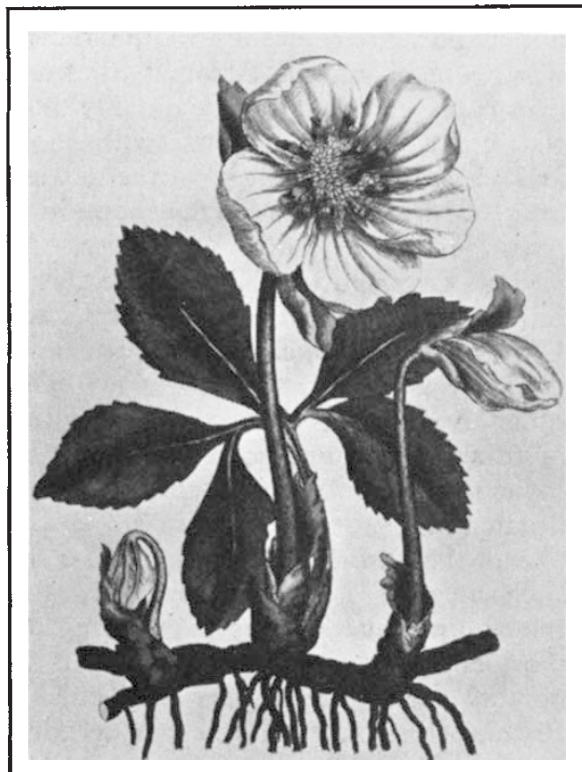

\section{Neoplastic development}

Neoplastic Development. Volume 2. By Leslie Foulds. Pp. xiv +729 . (Academic London and New York, August 1975). £16.80; $\$ 43.50$.

LESLIE Foulds spent most of his working life in experimental cancer research, but his interest in cancer extended beyond the laboratory. His object in writing this book is perhaps best given in his own words:

In any branch of science it is important to confront inferences from laboratory experiments with the stark realities of natural phenomena... It is especially important ... when the growing estrangement between clinical practice and laboratory research is leading to grave doubts about the ability of laboratory research, as now conducted, to make any substantial contribution to the alleviation of human suffering attributable to neoplastic disease. Writing from the standpoint of a medically qualified experimental pathologist with a long-standing interest
Illustrations taken from British Botanical and Horticultural Literature before 1800. By Blanche Henrey. Three Volumes. Pp. I,128. 32 colour plates, $162 \mathrm{pp}$. black and white illustrations. (Oxford University: London, 1975.) f70. A comprehensive account of book s and pamphlets on botany, gardening, horticulture, arboriculture and silviculture from the sixteenth to eighteenth centuries. Left, Helleborus niger $L$., Christmas Rose. Drawn and engraved by James Sowerby. From Medical Botany (1790), Vol. I by Woodville. Right, Lillium martagon L., Martagon or Mountain Lilly. Engraving from The Compleat Florist (1740).

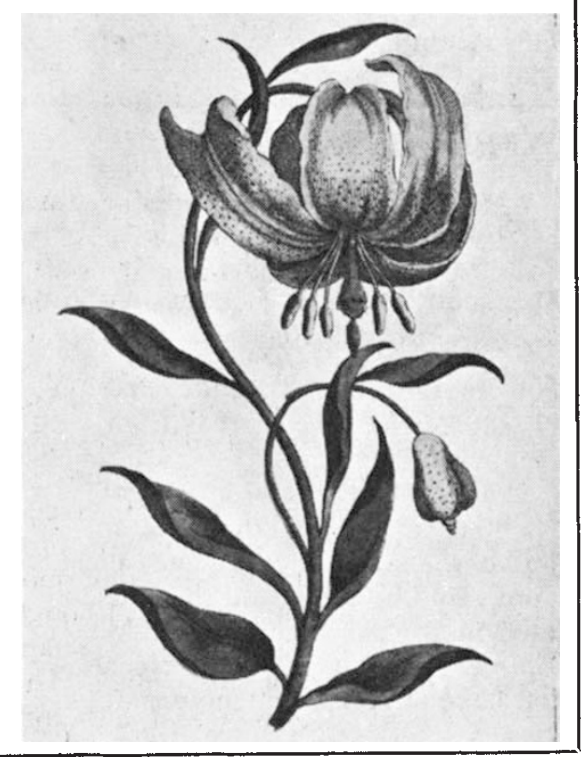

in both developmental biology and medical practice but with no direct participation in either, I hope to illustrate in this volume (Volume 2) the complimentary and essential, but diverse contributions, of biological theory, laboratory analysis and clinical experience of human disease.

Volume 1 provided a general theory, basically that neoplasis is a developmental process akin to normal development but differing from it in some important respects, still to be defined. In Volume 2, he considers special cases of neoplastic development in man, and animals, and discusses the biological and medical implications. After a brief general introduction, there are large sections on neoplasia of the skin, mammary neoplasia in laboratory animals and human breast cancer. Shorter sections deal with cancer of uterine cervix, urinary tract, lungs, liver and some endocrine glands, and there are two brief sections on neoplasia of unknown pathogenesis and virus tumours. The section on skin is the most extensive and is used to establish general principle concerned with the initiationpromotion theory and with tumour progression. The latter is illustrated by descriptions of the disease process in man and in the experimental animal, and a discussion on aetiology. A similar approach is used in the other sections.

Like its predecessor it is a valuable work and few of those interested in cancer in general or in one of the special fields discussed will fail to learn something of value. It will teach the clinician something of experimental cancer research and the research worker a little about human cancer, but in a major objective-a more rational approach to the clinical management of the patient-it must be regarded as a gallant failure, not through a fault of the author but through our ignorance. It is sad that the author should have died from cancer shortly before the book was published, and before he completed the final chapter summarising his views and general conclusions.

L. M. Franks 